\title{
O Japão frente à crise econômica e as relações nipo-brasileiras ${ }^{1}$
}

Ken Shimanouchi ${ }^{2}$

Boa noite a todos.

É com satisfação que aqui me encontro para expor um pouco sobre a relação Japão-Brasil que, nos últimos anos, vem se transformando e vive hoje uma fase singular. Agradeço primeiramente ao magnífico reitor Getúlio Américo Moreira Lopes, ao diretor Túlio Arantes, da Faculdade de Ciências Jurídicas e Sociais , à professora Renata de Melo Rosa, do curso de Relações Internacionais, e a todos os organizadores por esta oportunidade.

A centenária amizade entre o Japão e o Brasil, marcada por inúmeras comemorações no ano passado, envolveu os mais variados setores da sociedade brasileira. O grande momento da celebração foi a visita do príncipe-herdeiro Naruhito ao Brasil, em junho, quando esteve participando das cerimônias oficiais.

O Centenário foi uma valiosa oportunidade para muitos japoneses e brasileiros conhecerem melhor os respectivos países, fazendo com que a tradicional relação nipo-brasileira seja remodelada com novas características em termos de diversidade e qualidade. Nesse novo cenário de relacionamento, tanto o Japão quanto o Brasil tiveram as suas economias seriamente afetadas pela crise econômica desde o ano passado. Ambos os países sentiram o grande impacto causado por essa avalanche. No entanto, o Brasil mostrou uma rápida reação e já iniciou o processo de retomada de crescimento, puxando a recuperação da economia global. Por outro lado, o Japão, apesar de ter registrado grande queda no PIB, deverá sair da crise mais cedo do que outros países desenvolvidos.

Isto porque possui um sistema financeiro saudável, com um apreciável potencial tanto de capital como de tecnologia. Outro vento a favor do Japão é a rápida recuperação da economia da Ásia. A previsão é de que neste ano, a taxa de crescimento desta região alcance $5 \%$ positivos, enquanto que esse índice dos países do

\footnotetext{
${ }^{1}$ Palestra proferida pelo embaixador no Centro Universitário de Brasília em 19 de agosto de 2009.

${ }^{2}$ Embaixador do Japão no Brasil.
} 
G7 deverá se registrar uma redução de 3,5\%. Dentro desse contexto, as relações bilaterais avançam a passos vigorosos, sobretudo no campo econômico. A desaceleração do crescimento global não diminuiu o nível de relação entre os dois países. Muito pelo contrário, cada vez mais surgem novas oportunidades.

Os intercâmbios cultural e humano estão cada vez mais dinâmicos. Pode-se dizer que entramos numa nova era da relação Japão-Brasil.

A partir dessa ótica, hoje pretendo fazer uma revisão do relacionamento entre os dois países.

\section{Brasil de hoje sob a visão do Japão}

Este ano, em meus dois retornos ao Japão, tive a oportunidade de fazer palestras sobre o Brasil e trocar opiniões com líderes políticos e econômicos, além de vários especialistas. Nas palestras, sempre com público lotado, muitas perguntas foram feitas, demonstrando o interesse cada vez maior pelo Brasil. Essa tendência tem me impressionado muito.

Por quê esse grande interesse pelo Brasil?Não podemos falar do interesse japonês pelo Brasil sem nos referirmos à maior comunidade nikkei fora do Japão, ou ao "elo especial" construído através dos Projetos Nacionais como a Usiminas, a Albrás, o Desenvolvimento do Cerrado, entre as décadas de 60 e 80 . Porém, o mais surpreendente é o interesse que tem surgido após a crise financeira.

Para explicar esse fenômeno podemos citar o seguinte: em primeiro lugar, a crise financeira causou feridas, mas menos profundas do que em outros países, criando um cenário relativamente favorável ao mercado brasileiro. Melhor dizendo: criaram-se novas oportunidades de negócios.

Outro fato é a vantagem do Brasil vista a longo prazo. A sua estrutura econômica equilibrada mesmo com abundantes recursos naturais, a tecnologia própria, o grande mercado interno, as sólidas instituições democráticas, são alguns dos determinantes dessa vantagem. E com toda essa superioridade, não observamos nenhum risco de longo prazo, quando comparamos com outros países emergentes, além de estar compartilhando os valores e metas com demais democracias desenvolvidas do mundo. 
Definindo tudo isso em outras palavras: é o "Redescobrimento" do Brasil.

E, em terceiro lugar, a ratificação de que as relações especiais dos dois países têm adquirido uma nova significância no contexto contemporâneo. Nesse sentido, é desnecessário salientar o relevante papel desempenhado pelo Centenário da Imigração Japonesa no Brasil.

\section{A atual situação da economia japonesa}

Agora, vou falar um pouco sobre a situação atual da economia japonesa.

A economia do Japão está se recuperando da pior recessão desde a Segunda Guerra Mundial. O mercado da bolsa de valores que sofreu queda brusca após setembro do ano passado já voltou ao mesmo patamar de antes da crise.

De acordo com as estatísticas mais recentes divulgadas pelo Governo no dia 17 de agosto, o PIB do segundo trimestre de 2009 fechou com alta de 3,7\%, em termos anualizados. O índice de produção industrial que vinha em queda consecutiva também vem se recuperando, alcançando números positivos.

Hoje, uma nova demanda tem surgido no mercado japonês. Os consumidores japoneses cada vez mais sensíveis às questões ambientais, estão aquecendo o mercado de automóveis, mas sem o aquecimento global. Os chamados veículos ecologicamente corretos como os carros híbridos e elétricos são as novas vedetes no Japão. Principalmente o Prius da Toyota e o Insight, da Honda são os carros híbridos mais preferidos. No ranking de venda de carros novos do Japão, de junho passado, o Prius ocupou a primeira posição e o Insight a quarta. O Prius da Toyota é tão procurado que o tempo de espera é de mais de seis meses, correndo o risco de não poder aproveitar o subsídio oferecido pelo Governo Japonês na compra desse tipo de carro, cujo prazo termina em março do próximo ano.

Em julho deste ano, a Mitsubishi Motors lançou o seu primeiro carro elétrico, $i-M i E V$, e a Nissan o Leaf, em agosto, sendo os pioneiros no mundo. Esta popularidade dos carros ecológicos contribui também para a geração de emprego, uma vez que a indústria automobilística é um dos motores propulsores da economia japonesa. 
Outro segmento que está impulsionando a atual economia japonesa é o de eletrodomésticos com baixo consumo de energia. Em abril passado, o Governo Japonês anunciou o sistema de "Eco-Pontos”. Esse sistema é semelhante ao programa de milhagens das companhias aéreas. Na compra de determinados aparelhos eletroeletrônicos como ar-condicionado, geladeira, TV digital, serão computados pontos equivalentes à capacidade e volume de cada aparelho.

No caso da TV de tela fina, são até $10 \%$ do valor, os demais recebem $5 \%$. Ao acumular esses pontos, o consumidor poderá permutar com produtos elétricos e outros artigos como cupons de viagens, etc.

Essa medida incentiva os consumidores a optarem por produtos cada vez mais ecológicos, contribuindo para a formação de uma sociedade de baixo carbono. Outro fator que deverá ajudar o Japão a recuperar a sua economia antes do que outros mercados como os dos Estados Unidos ou da Europa, é o seu sistema financeiro saudável, assim como é o caso do Brasil. Quero mencionar também, a poupança individual dos japoneses, como alavanca para puxar a economia do país. O total da poupança soma 15 trilhões de dólares, número equivalente ao PIB dos Estados Unidos. O Japão se esforça em ampliar a demanda interna, porém, numa sociedade que envelhece e nascem poucas crianças, e conseqüente diminuição demográfica, existe um limite. Nesse contexto, os mercados emergentes são cada vez mais atrativos. O Brasil é um desses mercados, e, dentre os poucos que conseguem se manter nesse patamar, o Brasil se reposiciona como principal vetor econômico de expansão.

\section{A atual relação Japão-Brasil e sua perspectiva}

A relação econômica entre o Japão e o Brasil vêm se estreitando num ritmo acelerado após o período considerado como "as duas décadas perdidas", a partir dos anos 80 .

Com a crise mundial, um número pequeno dos projetos de investimentos japoneses no Brasil teve que ser adiado. No entanto, outros que existiam antes da crise continuam firmes, e mais novos projetos são apresentados. São tantos os projetos japoneses nos mais diversos setores do Brasil que fica difícil visualizar o quadro geral. 
Agora, farei um breve apanhado sobre as principais cooperações econômicas entre os dois países.

Os tradicionais setores como a siderurgia, o alumínio, e a celulose sofreram os impactos da crise financeira. Porém estão a caminho da recuperação cujas perspectivas a longo prazo são muito promissoras.

O mercado automobilístico do Brasil é um dos mais robustecidos, e as montadoras japonesas também visam expandir sua presença, lançando novos modelos sucessivamente.

O potencial do agronegócio brasileiro, o maior do mundo, deverá atingir um elevado nível de importância no mercado japonês. Atualmente, 95\% do frango e 74\% do suco de laranja que o Japão importa são do Brasil.

Já no campo da energia, as atenções serão ainda maiores. A Petrobrás e as empresas japonesas já têm parceria em grandes escalas, nos diversos campos. A atuação das empresas japonesas vai além de financiamentos, participando de todas as etapas, desde a escavação, produção, até o refino. Projetos como os do etanol, sua produção, transporte e exportação, estão em constante atividade. O Japão desempenha papel crescente nesta área.

Outro projeto inovador que abriu novos horizontes na cooperação econômica nipo-brasileira é a TV Digital. Os nossos países se engajaram num trabalho conjunto para a implantação do padrão japonês de TV digital no Brasil, o que resultou num grande êxito. Esse desenvolvimento nipo-brasileiro tem sido difundido na América do Sul e, recentemente, o Perú oficializou a adoção desse sistema. Outros países da América do Sul também estudam fazer o mesmo.

Esse sistema, cuja vantagem comparativa com demais padrões é bem evidente pela sua alta definição, mobilidade e outras qualidades, tem recebido altíssimo conceito. Com essa mobilidade, os brasileiros serão um dos poucos no mundo que poderão torcer pela vitória do Brasil na próxima Copa do Mundo pelo celular, e, ao mesmo tempo, apreciar as novelas com imagens de alta definição da TV.

Todos poderão sentir essa grande diferença como quando comparam as televisões coloridas com as de preto e branco. A cooperação nipo-brasileira na 
TV digital é única no mundo. Podemos fazer dessa colaboração bilateral um modelo para aplicar em outras áreas de cooperação. Outro campo de cooperação que merece engajamento mútuo são os negócios ecológicos, onde ambos os países poderão envidar o máximo de seu potencial.

Tentarei ilustrar com exemplos.

O Brasil é o lider mundial em energia limpa, enquanto que o Japão é o maior em eficiência energética.

No Brasil, os raios de sol são uma dádiva ilimitada e existe grande potencialidade de painéis solares se tornar a nova fonte de energia. Por outro lado, o Japão tem investido na tecnologia de geração de energia solar, cuja produção da bateria solar está entre as primeiras do mundo.

Assim, a parceria nipo-brasileira na geração da energia solar é um campo com ampla possibilidade de exploração. A energia eólica também abre portas à nova cooperação. As altas tecnologias do Japão e do Brasil nessa área poderão ajudar a desenvolver essa fonte energética no extenso litoral brasileiro.

Como já mencionei, o Japão está apostando maciçamente nos aparelhos com baixo consumo de energia. A produção desses aparelhos ecológicos se iniciou no país há bastante tempo. portanto é possível perceber os efeitos ecológicos dos produtos japoneses muito mais do que os de outros países.

Um exemplo disso é a TV japonesa da tela fina. A última geração deste tipo de aparelho possibilitou reduzir em $45 \%$ o consumo de energia em comparação aos modelos anteriores. Assim, o Japão e o Brasil poderiam formar parcerias na fabricação de eletrodomésticos ecologicamente corretos. Outro setor de cooperação bastante promissor é a indústria automobilística. A combinação da tecnlogia pioneira dos carros flex do Brasil com a dos híbridos do Japão, resultaria num veículo últra-ecológico. Em março, a Honda lançou a motocicleta flex no Brasil, primeira no mundo que utiliza o biocombustível. A demanda foi maior do que a esperada, e foram vendidas 66 mil unidades somente nos primeiros 3 meses. Este é um exemplo de colaboração das tecnologias ecológicas dos dois países que deu muito certo. O mais novo destaque de cooperação ecológica é o Projeto do Trem de Alta Velocidade entre Rio de Janeiro, São Paulo e Campinas. 
O grande ponto a favor do Shinkansen, o Trem de Alta Velocidade japonês, é que este polui bem menos do que os outros modelos concorrentes. Especificando, o vagão do Shinkansen é tão leve que gasta muito pouca energia por passageiro, emitindo menos $\mathrm{CO} 2$. Em termos comparativos, o consumo de energia calculado por passageiro, corresponde a um quarto do de um avião, e a um sexto do de um carro. A emissão de $\mathrm{CO} 2$ é seis vezes menor do que a do avião, e dez vezes menor do que a de um carro.

Além disso, o Shinkansen é super silencioso, cumprindo um padrão de sonoro mais rigoroso do que o permitido na Europa. Na escavação de túneis, no caso do Shinkansen, basta um mínimo de diâmetro, o que acarreta na diminuição tanto de material como de custos das obras.

Além dessas características benéficas ao meio ambiente, o modelo Shinkansen possui superioridade técnica no que tange à segurança e capacidade de transporte em massa. Estou convicto de que o modelo japonês de Shinkansen é o mais adequado ao Brasil.

O Brasil não apenas lidera a economia mundial, mas a sua maturidade democrática, o respeito aos direitos humanos, a ausência de conflitos internos graves permitem alçar voos maiores na sociedade internacional. Essa superioridade do Brasil lhe confere estatura moral para assumir a liderança entre os países emergentes. O proeminente papel do Brasil cada vez maior na comunidade internacional deverá proporcionar benefícios para todo o mundo. O Japão deseja encarar os desafios internacionais estreitando a colaboração com o Brasil, além de fortalecer a parceria econômica.

Ambos os países compartilham os valores básicos como democracia, respeito aos direitos humanos e economia de mercado.

Como duas grandes potências não possuidoras de armas nucleares que prezam a paz, compartilham também princípios básicos comuns. Com essa política fundamental, podemos qualificar os dois países como "líderes morais" no contexto mundial.

Naturalmente, sendo duas grandes nações que preservam o meio ambiente, existem muitas questões ambientais a serem resolvidas juntos, como a mudança climática. A parceria Japão-Brasil nos projetos de desenvolvimento dos países da 
África, trará grandes benefícios a todos os envolvidos. Em suma, chegou a era da globalização das relações nipo-brasileiras. Durante os 38 anos de minha carreira diplomática, servi em nove missões, incluindo o Brasil. A minha vida aqui tem sido bastante intensa, devido aos pujantes comércio e investimento bilaterais, bem como os intensos ir e vir dos dois povos. Não existe outro país capaz de reunir mais de 100 mil pessoas em festas japonesas. O Brasil é o único no mundo com tantos amantes da cultura japonesa. O mundo está sofrendo grande transformação por causa da crise financeira. Nesse cenário, tanto o Japão quanto o Brasil buscam delinear um novo formato como nação.

A única afirmação possível é a de que as relações nipo-brasileiras se aproximam de maneira muito veloz e que ambos os países se encontram num patamar importante.

Estão numa posição onde é esperada a contribuição conjunta para a recuperação e prosperidade da economia mundial, bem como a paz e a estabilidade da comunidade internacional.

Ao finalizar, quero lembrar a todos que após as comemorações do Centenário, neste ano, a imigração japonesa está completando 80 anos na Amazônia.

Em setembro próximo, mês em que as primeiras famílias japonesas chegaram em Belém, seguindo para o município de Tomé-Açu e outras regiões, solenidades e atividades culturais irão celebrar as datas. Os estados do Pará, Amazonas e Roraima vão homenagear os pioneiros imigrantes. Convido a todos para se juntarem a eles e celebrar mais este importante episódio da relação Japão-Brasil.

Considero-me muito feliz e honrado por ser Embaixador do Japão no Brasil, exatamente neste excelente momento da historia dos dois países.

Muito obrigado pela atenção. 